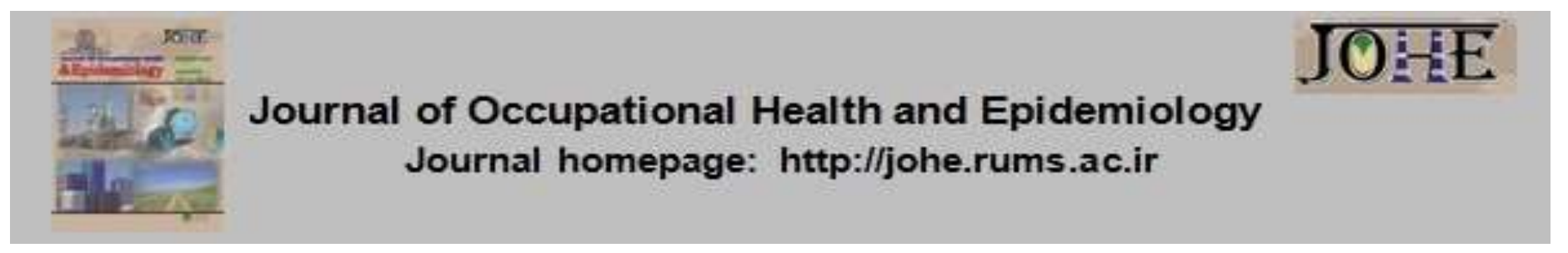

\title{
The association between health literacy and self-medication behaviors among women referred to comprehensive health care centers in Sirjan, Iran, in 2017
}

\author{
Somayeh Mousaeipour ${ }^{1}$, Ali Ansari Jaberi², Tayebeh Negahban Bonabi $3^{3^{*}}$
}

1- M.Sc. Medical Surgical Nursing Student. Department of Medical Surgical Nursing, School of Nursing and Midwifery; Student Research Center, Rafsanjan University of Medical sciences, Rafsanjan, Iran.

2- Msc; Department of Psychiatric and Mental Health Nursing, School of Nursing and Midwifery; Social Determinants of Health Research Center, Rafsanjan University of Medical sciences, Rafsanjan, Iran.

3- Assistant professor, Department of Community Health Nursing, School of Nursing and Midwifery; Social Determinants of Health Research Center, Rafsanjan University of Medical sciences, Rafsanjan, Iran.

Article Info

* Corresponding authors:

Tayebeh Negahban Bonabi,

E-mail:

negahbant@yahoo.com

\section{Article history}

Received: March, 2018

Accepted: April, 2018

10.29252/johe.7.2.103

Print ISSN: 2251-8096 Online ISSN: 2252-0902

Peer review under responsibility of Journal of Occupational Health and Epidemiology
Citation: Mousaeipour S, Ansari Jberi A, Negahban Bonabi T. The association between health literacy and self-medication behaviors among women referred to comprehensive health care centers in Sirjan City, Iran, in 2017. JOHE. 2018; 7(2):103-111.

\begin{abstract}
Background: Self-medication is a challenging issue in health care systems and it seems that health literacy is a determining factor in safe self-medication behaviors. Limited studies are available in this field. Therefore, the aim of this study was to determine the relationship between health literacy and self-medicating behaviors among women referred to comprehensive health care centers

Materials and Methods: In this descriptive study, 540 women, who were referred to comprehensive health care centers in 2017 , were selected randomly and their health literacy and self-medicating behaviors were assessed through self-reporting method. The data collection tools were the standard Health Literacy for Iranian Adults (HELIA), and the self-medication behaviors questionnaires. Data were analyzed using chi-square, MannWhitney $\mathrm{U}$, and Kruskal-Wallis $\mathrm{H}$ tests.

Results: The results showed that the majority of women $(94.6 \%)$ had inadequate health literacy. More than $89 \%$ of them approved self-medication and more than $98 \%$ of them performed self-medication. Older women and those who had a higher education level had lower mean health literacy scores $(P=0.021$ and $P=0.001$, respectively). There was no significant relationship between self-medication and demographic characteristics. Furthermore, there was no significant relationship between health literacy and confirmation and performance of self-medication.

Conclusions: The women had low health literacy levels and high incorrect selfmedication behaviors. Self-medication behaviors are performed independent of health literacy. It seems a reform in women's health programs and the empowerment of women in the target population is necessary in order to promote health literacy skills and appropriate self-medication behaviors.
\end{abstract}

Keywords: Self Medication, Health Literacy, Empowerment, Women Health, Iran.

\section{Introduction}

Self-medication has been recognized as the most common form of self-care worldwide (1). It is defined as the self-prescription of medication to solve health problems without expert help or opinion (2). This is usually performed using synthetic or hand-made medicines following the advice of unprofessional individuals, including the use of previous prescriptions for themselves or friends and family members, re-use of existing drugs at home, and noncompliance with the prescribed treatment program or the prescribed 
dose change (3). The World Health Organization (WHO) has defined self-medication as the "the selection and use of medicines by individuals to treat self-recognized illnesses or symptoms" (4). The incidence of self-medication in different countries varies according to the extent of their development and has been reported between $4 \%$ and $98 \%$ in the results of studies (3,5-10). Poor countries face an increasing trend of selfmedication due to the high incidence of diseases and the lack of medical facilities (11). In a review study, the overall incidence of self-medication in Iran has been estimated as 53\% (12).

Today, self-medication is an important and challenging phenomenon in health care systems. From a viewpoint, self-medication leads patients to independence in decision-making and management of minor illnesses through empowerment. This will increase the patients' access to medicine, improve the disease symptoms, and establish their active role in their own health care. It also has benefits for the health care system, including facilitating the use of clinical skills, increasing access to medication, and reducing the cost of prescribing drugs. Nevertheless, self-medication cannot be regarded as a completely safe action, rather it has potential risks, including misdiagnosis, increased use of medications, long-term use of medication, drug interference $(13,14)$, delay in the search for appropriate treatment and medical advice, use of an unnecessary high dose of medication, presentation of rare, but serious and dangerous side effects, incorrect treatment selection, masking serious diseases, risk of dependence and drug abuse, resistance to antibiotics, and increased health costs due to an increase in mortality rates and increased length of hospitalization that can be problematic in some vulnerable groups, including the elderly (15).

In various studies, numerous factors have been introduced to predict self-medication behaviors, including age, sex (7), marital status, depression, activity limitation, life satisfaction (10), education level, income level, place of residence and awareness level (16), past experiences of selfmedication and self-assessment of health status (17), cost saving (18), smoking and alcohol drinking, chronic illness, self-efficacy, and low drug literacy (17). Health literacy is associated with the ability of individuals to acquire, understand, and use information for health promotion (19), the situation that happens during the self-medication process according to most researchers; therefore, it seems that health literacy level is a determining factor in the occurrence of self-medication behaviors $(20,21)$.
Reviewing the existing literature indicated that there are a limited number of studies regarding the relationship between health literacy and incidence of self-medication behaviors. The results of some existing studies indicate that health literacy has a positive relationship with drug literacy and safe use of drugs (22). In another study, researchers also reported higher levels of health literacy among patients performing self-medication (23). The findings of studies have shown that women are active health information searchers $(24,25)$ and they are more sensitive to their health and preventive measures compared to men $(6,26,27)$, and hence, they try self-medication for themselves and family members more than men $(6,28)$. Thus, it can be said that they play a very significant role in family health care. Considering that most human behaviors are influenced by beliefs, creed, and customs based on the cultural and social context of societies (29), self-medication behaviors can also appear in different societies with different patterns. The researchers in the present study did not find a similar study in Iran investigating the relationship between health literacy and the occurrence of self-medication behaviors. Therefore, this study focused on women's health literacy and self-medication behaviors and was conducted with the aim of determining the relationship between health literacy and selfmedication behaviors of women covered by comprehensive health services centers in Sirjan City, Iran.

\section{Material and Methods}

In this descriptive study, the relationship between health literacy and self-medication behaviors of women covered by comprehensive health services centers in Sirjan City was investigated. The study was carried out during the 5 months from August to December 2017. The study was first approved by the research council of Rafsanjan University of Medical Sciences, Iran, with the ethics code of IR.RUMS.REC.1396.85. Subsequently, the researchers referred to the health department of the School of Medicine of Sirjan University of Medical Sciences, and then, to the health centers (6 comprehensive urban health care centers and 19 health bases) and presented the letter of introduction to these places, then, they started sampling. First, the sample proportion for each center was determined based on the population of women covered by each center, and then, the samples were selected using the SIB integrated health system based on the table of random numbers. In the next step, the selected women were invited through telephone call to attend the center and participate in the study. After attending 
the center, the research objectives were explained to the participants and they were assured of the confidentiality of the recorded information, then, they were entered into the study if they were willing to participate and had signed the informed consent form.

The study inclusion criteria were age of 18 to 65 years, minimum reading and writing literacy, willingness to participate in the study, and lack of permission for prescribing drugs. In addition, the exclusion criteria included the lack of willingness to complete the questionnaire, inability to answer questions, and incomplete answering of the questionnaire.

The sample size was estimated to be approximately 546 individuals based on the review of the literature, taking into account the 95\% confidence coefficient $\left(Z_{1-\frac{\alpha}{2}}=1.96\right)$, the accuracy of $0.04(d=0.04)$, and also the adequate level of health literacy $(P=35 \%)(30)$, and using the formula:

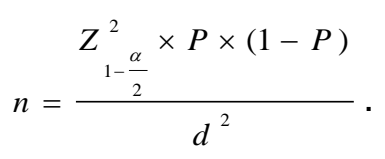

The data collection tools included a demographic characteristics questionnaire including questions on age, occupation, education, marital status, and number of children, and a two-part questionnaire. The two-part questionnaire consisted of the standard Health Literacy for Iranian Adults (HELIA) questionnaire among the urban population of Iran (18 to 65 years old) and the self-medication behaviors questionnaire. The HELIA questionnaire was published by Montazeri et al. in 2014 and consisted of 33 items in the 5 dimensions of reading, access, comprehension, assessment, and decision-making and behavior with 4, 6, 7, 4, and 12 items, respectively. The questions are scored based on a 5-point Likert scale ranging from 5-1 (always, most often, sometimes, rarely, and never, respectively). The score of each individual in the subscales was obtained from the sum of the scores; then, according to the tool instruction, these scores were converted to the $0-100$ range according to the following formula.

Minimum possible raw score - Obtained raw score Minimum possible score - Maximum possible score

To calculate the total score, the scores of the subscales (based on the 0-100 range) were summed up and the result was divided by 5 (number of subscales). To rank the health literacy level, the scores of 0 to $50,50.1$ to $66,66.1$ to 84 , and 84.1 to 100 are considered to indicate inadequate, not very adequate, adequate, and excellent levels, respectively. This questionnaire has an acceptable validity level and has acquired a reliability of $89 \%$ (31).

In this study, self-medication indicated willful treatment with chemical drugs. A researcher-made questionnaire was used to assess the selfmedication behaviors among women that contained 22 items regarding the confirmation and performance of self-medication and details of selfmedication behaviors. Both the qualitative and quantitative methods were exploited to determine the content validity of the tool. Regarding the qualitative validity investigation, the tool was provided to 10 professors and specialists in health sciences and they were asked to give their comments in writing regarding content comprehensiveness, grammar observance, use of suitable expressions, and appropriate location of the items. Similarly, the content validity ratio (CVR) and content validity index (CVI) were used in order to evaluate the content validity quantitatively (32). In the process of the quantitative evaluation of the validity of the questionnaire, 3 and 19 questions were eliminated and retained due to their CVR values of below 0.49 and over 0.49 , respectively (32). Finally, the reliability of the questionnaire was confirmed with a mean CVR of 0.66 and the mean total content CVI of 0.94 . The internal reliability of the tool based on all the questionnaires was confirmed by the Cronbach's alpha coefficient of 0.92 . The questionnaires were completed by the women through self-report method; however, if the subjects did not have enough time to fill in the questionnaire, the questionnaire was completed through face-to-face interviews.

Data were analyzed using the chi-square, KruskalWallis $\mathrm{H}$, and Mann-Whitney $\mathrm{U}$ tests in SPSS software (version 20, IBM Corporation, Armonk, NY, USA).

\section{Results}

A total of 540 questionnaires were eligible for analysis and 6 questionnaires were excluded from the study due to incomplete response. There was no case of exclusion during the course of responding to the questionnaires. The mean and standard deviation (SD) of the participants' age was $32.22 \pm 8.28$ with a minimum and a maximum age of 18 and 59 years, respectively. In terms of marital status, the vast majority of the women (527; $97.6 \%)$ were married. Moreover, 496 of the women $(91.9 \%)$ were housewives. Furthermore, 275 $(50.9 \%)$ participants were university graduates and only $4.1 \%$ had undergraduate or graduate degrees 
in medical sciences. In addition, 467 (86.5\%) of the women under investigation had at least 1 child at home at the time of the study. Monthly income of 236 (43.7\%), 172 (31.9\%), and 132 (24.4\%) participants was under 1 million tomans, between 1 and 2 million tomans, and higher than 2 million tomans, respectively.

Regarding the health literacy level, the mean and SD of the total health literacy score of the women was $27.93 \pm 12.89$ with a minimum and maximum of 0 and 65.83, respectively. Assessing the scores of the subscales revealed that the dimensions of reading, access, comprehension, assessment, and decision-making and behavior had a mean and SD of $26.59 \pm 18.35$ (minimum and maximum: 0 and 100), $31.08 \pm 16.38$ (minimum and maximum: 0 and 95.83), $19.86 \pm 13.89$ (minimum and maximum: 0 and 67.86), $32.04 \pm 18.64$ (minimum and maximum: 0 and 100 ), and $30.22 \pm 16.56$ (minimum and maximum: 0 and 77.08), respectively. The distribution of the absolute and relative frequencies of the total health literacy levels and its sub-scales has been presented in table 1 . Based on this table, the vast majority of the women were in the "inadequate" level in terms of the score of total health literacy and its subscales (Table 1).

Table 1: Distribution of absolute and relative frequencies of the total health literacy levels and its sub-scales among women covered by comprehensive health services centers of Sirjan City, Iran, in 2017

\begin{tabular}{|c|c|c|c|c|}
\hline \multirow{2}{*}{ Health literacy levels } & \multicolumn{4}{|c|}{ Rate (\%) } \\
\hline & Inadequate & Not very adequate & Adequate & Excellent \\
\hline Total health literacy & $511(94.6)$ & $29(5.4)$ & 0 & 0 \\
\hline Reading dimension & $506(93.7)$ & $21(3.9)$ & $12(2.2)$ & $1(0.2)$ \\
\hline Access dimension & $494(91.5)$ & $29(5.4)$ & $14(2.56)$ & $3(0.6)$ \\
\hline Comprehension dimension & $531(98.3)$ & $8(1.5)$ & $1(0.2)$ & 0 \\
\hline Assessment & $465(86.1)$ & $51(9.4)$ & $22(4.1)$ & $1(0.4)$ \\
\hline Decision-making & $487(90.2)$ & $43(8)$ & $10(1.9)$ & 0 \\
\hline
\end{tabular}

The results regarding the investigation of selfmedication among women and the rate of selfmedication behaviors revealed that $471(89.1 \%)$ of women confirmed performing self-medication to some degree and 534 (98.9\%) of them performed self-medication. Approximately half of the women participating in the study (236 women; 43.7\%) always studied the instructions inside the drug box, and about 524 (98.9\%) checked the date of expiry of their medications to somedeal. In addition, a change in the dosage was reported by 371 $(68.7 \%)$ of the women. Moreover, 457 (84.9\%) changed the type of prescribed medication.

The results of examining other self-medication behaviors of women showed that 288 (53.3\%) of them responded the option always to the question "When do you take medicine without a prescription?" and only $6(1.1 \%)$ women had chosen the rarely option. About 232 (43.0\%) women received information for self-medication from pharmacies, $136(25.2 \%)$ used their personal experiences, and 66 (12.2\%), 55 (10.2\%), and 51 $(9.4 \%)$ of the women, respectively, received this information from the public media, health workers, and relatives and friends. Approximately 400 (74.0\%), 121 (22.4\%), and 19 (3.6\%) of the women obtained medicines required for self-medication from pharmacies, the existing drugs at home, and friends and relatives and stores, respectively. In response to the question "Which medicines do you often use for self-medication?", the pain killers accounted for the highest rate with 252 (46.7\%), followed by antibiotics (126; 23.3\%), anti-allergy drugs $(69 ; 12.8 \%)$, vitamins $(44 ; 8.1 \%)$, and hypnotics (10; 1.8\%). In addition, 39 (7.3\%) women had chosen other options.

Among the participants, 245 (45.4\%), 184 (34.1\%), $14(6.2 \%)$, and 97 (17.9\%) women used selfmedication for cold relief, pain relief, insomnia, and other cases, respectively. In response to the question "What is your most important reason for self-medication?”, 198 (36.7\%), 105 (19.4\%), 82 (15.2\%), 53 (9.8\%), $13(2.4 \%)$, and $89(6.5 \%)$ of the subjects selected mild problem, cost saving, lack of time, emergency conditions, distrust of physicians, and other cases, respectively.

In response to the question "What consequences of self-medication do you often encounter?", 278 (51.5\%), 129 (23.9\%), 85 (15.8\%), $17(3.1 \%)$ of the women reported relief of disease symptoms, disease treatment, disease prevention, and worsening of symptoms, respectively. Moreover, self-medication did not have any outcome among $31(5.7 \%)$ of the subjects. About 233 (43.1\%) women tried to manipulate the type and dosage of the drug after relieving of the symptoms, and more than half of them announced the lack of drug effectiveness and worsening of the disease symptoms as the reasons for changing the type and dosage of the drug. Furthermore, 238 (44.1\%) women referred to the medication guide to determine the drug dose during self-medication.

Comparing the health literacy of women participating in the study in terms of demographic 
characteristics (including age groups, monthly income level, marital status, occupation, education level, and field of study) indicated no significant difference except in terms of age and educational level (Table 2).

Table 2: Comparison of health literacy level among women covered by comprehensive health services centers of Sirjan City, Iran, in 2017 in terms of age groups and educational level

\begin{tabular}{cccc}
\hline \multicolumn{2}{c}{ Variables } & $\begin{array}{c}\text { Overall health literacy } \\
\text { (Mean } \pm \text { SD) }\end{array}$ & P \\
\cline { 2 - 4 } & $\mathbf{1 8 - 3 5}$ & $11.9 \pm 27.07$ & \\
\cline { 2 - 4 } Age (year) & $\mathbf{3 6 - 4 5}$ & $14.28 \pm 28.39$ & $0.021^{*}$ \\
\cline { 2 - 4 } & $\mathbf{> 4 5}$ & $2.14 \pm 14.41$ & \multirow{2}{*}{$0.001^{* *}$} \\
\hline \multirow{2}{*}{ Education } & Diploma and below & $13.09 \pm 33.75$ & $0.89 \pm 22.33$ \\
\cline { 2 - 4 }
\end{tabular}

SD: Standard deviation; * Kruskal-Wallis $\mathrm{H}$ test; ${ }^{* *}$ Mann-Whitney $\mathrm{U}$ test

Comparison of self-medication among women participating in the study in terms of demographic characteristics (age groups, monthly income level, marital status, occupation, education level, and field of study) showed no statistically significant difference $(P>0.050)$.

Table 3: Relationship between some self-medication behaviors and health literacy levels among women covered by comprehensive health services centers of Sirjan City, Iran, in 2017

\begin{tabular}{|c|c|c|c|c|}
\hline \multirow[b]{2}{*}{ Variables } & & \multicolumn{2}{|c|}{ Health literacy levels } & \multirow[b]{2}{*}{${ }^{*} \mathbf{P}$} \\
\hline & & $\begin{array}{l}\text { Inadequate } \\
\text { Rate (\%) } \\
\end{array}$ & $\begin{array}{c}\text { Not very adequate } \\
\text { Rate (\%) } \\
\end{array}$ & \\
\hline \multirow{4}{*}{ Do you perform self-medication? } & Always & $274(50.8)$ & $14(2.6)$ & \multirow{4}{*}{0.642} \\
\hline & Mostly & $72(13.3)$ & $3(0.6)$ & \\
\hline & Sometimes & $159(29.4)$ & $12(2.2)$ & \\
\hline & Never & $6(1.1)$ & $0(0)$ & \\
\hline \multirow{4}{*}{$\begin{array}{l}\text { Do you confirm performing self- } \\
\text { medication? }\end{array}$} & Always & $64(11.9)$ & $4(0.7)$ & \multirow{4}{*}{0.913} \\
\hline & Mostly & $168(31.2)$ & $8(1.5)$ & \\
\hline & Sometimes & $223(44.4)$ & $13(2.4)$ & \\
\hline & Never & $55(10.2)$ & $5(0.9)$ & \\
\hline \multirow{4}{*}{$\begin{array}{l}\text { Do you change drug type during self- } \\
\text { medication? }\end{array}$} & Always & $12(2.2)$ & $4(0.7)$ & \multirow{4}{*}{0.021} \\
\hline & Mostly & $65(12)$ & $5(0.9)$ & \\
\hline & Sometimes & $350(64.9)$ & $22(4.1)$ & \\
\hline & Never & $81(15)$ & $1(0.2)$ & \\
\hline \multirow{4}{*}{$\begin{array}{l}\text { Do you change drug dosage during } \\
\text { self-medication? }\end{array}$} & Always & $10(1.9)$ & $6(1.1)$ & \multirow{4}{*}{0.001} \\
\hline & Mostly & $51(9.5)$ & $11(2)$ & \\
\hline & Sometimes & $282(52.1)$ & $11(2)$ & \\
\hline & Never & 178(31.2) & $1(0.2)$ & \\
\hline \multirow{4}{*}{$\begin{array}{l}\text { Do you check the date of expiry of } \\
\text { drugs used for self-medication? }\end{array}$} & Always & $361(67)$ & $13(2.4)$ & \multirow{4}{*}{0.001} \\
\hline & Mostly & $100(18.2)$ & $5(0.9)$ & \\
\hline & Sometimes & $44(2.8)$ & $11(2)$ & \\
\hline & Never & $5(0.9)$ & $2(0.4)$ & \\
\hline \multirow{4}{*}{$\begin{array}{l}\text { Do you read the instructions in the } \\
\text { medicine box for self-medication? }\end{array}$} & Always & $234(43.4)$ & $2(0.4)$ & \multirow{4}{*}{0.001} \\
\hline & Mostly & $168(31.2)$ & $5(0.9)$ & \\
\hline & Sometimes & $95(17.6)$ & $17(3.2)$ & \\
\hline & Never & $13(2.4)$ & $5(0.9)$ & \\
\hline
\end{tabular}

\section{${ }^{*}$ Chi-square test}

The results of the data analysis indicated no statistically significant relationship between confirmation and performance of self-medication by women and their health literacy levels. Regarding the investigation of the relationship of other self-medication behaviors with health literacy levels, the results of the data analysis showed that there was a significant statistical relationship between health literacy level and referring to the instructions contained in the drug box and also checking the expiry date of the drugs $(P=0.001)$, so that women with inadequate health literacy 
referred more to the instructions in the drug box and checked the expiry date of the drug. Manipulation of the drug type $(P=0.021)$ and drug dose $(P=0.001)$ were significantly higher among women with inadequate health literacy (Table 3). In addition, the results of the data analysis showed that the method of determining the dosage of self- medication drugs taken by the women under study $(P=0.001)$ and the resource of information on keeping self-medication drugs at home $(P=0.024)$ had a statistically significant relationship with their health literacy levels (Table 4).

Table 4: Relationship of self-medication drugs dosage and some self-medication behaviors with health literacy levels among women covered by comprehensive health services centers of Sirjan City, Iran, in 2017

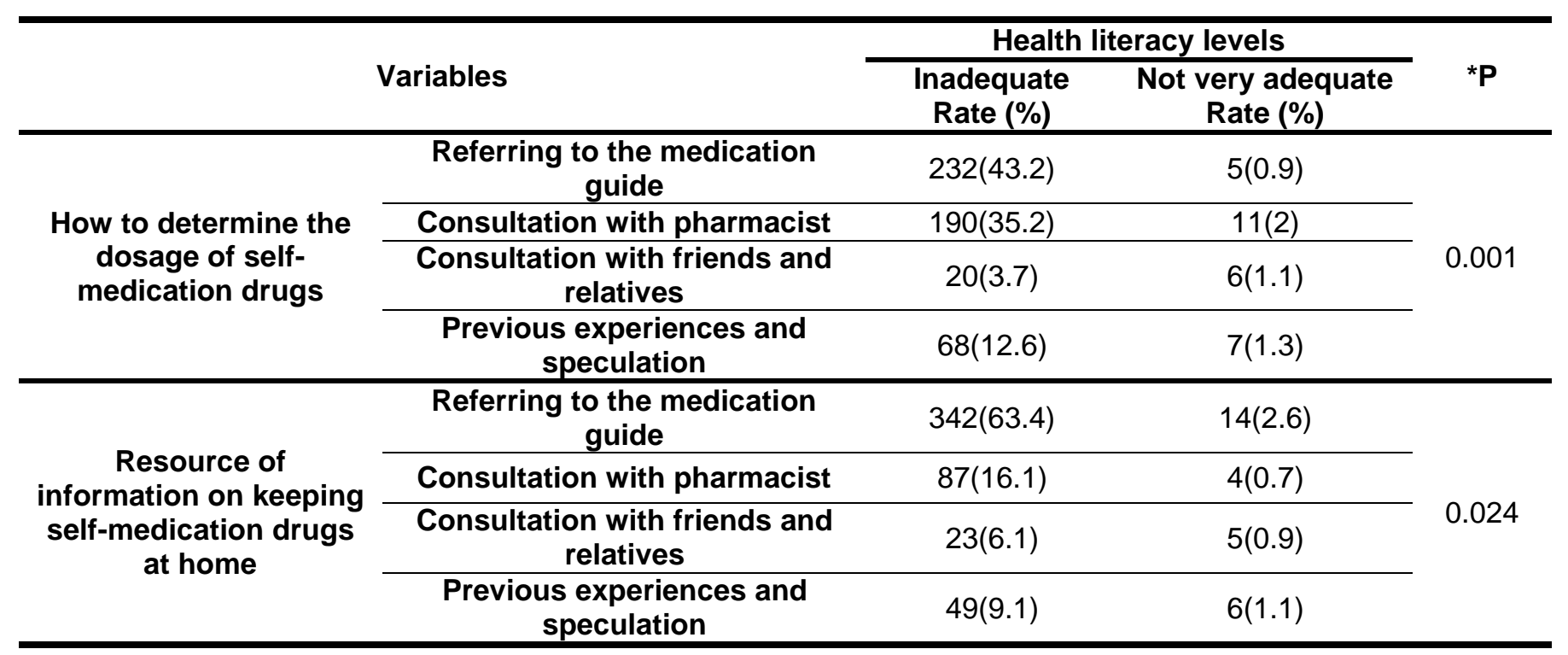

${ }^{*}$ Chi-square test

There was a significant relationship between the reasons for changing the dosage of drugs and women's health literacy levels $(P=0.005)$ (Table
5). However, no significant relationship was found between the other self-medication behaviors and the women's health literacy level $(P>0.050)$.

Table 5: Relationship between the reasons for changing the dosage of drugs and health literacy levels among women covered by comprehensive health services centers of Sirjan City, Iran, in 2017

\begin{tabular}{|c|c|c|c|c|}
\hline \multirow{2}{*}{\multicolumn{2}{|c|}{ Variables }} & \multicolumn{2}{|c|}{ Health literacy levels } & \multirow[b]{2}{*}{$\mathbf{P}^{*}$} \\
\hline & & $\begin{array}{c}\text { Inadequate } \\
\text { Rate } \\
(\%)\end{array}$ & $\begin{array}{l}\text { Not very } \\
\text { adequate } \\
\text { Rate }(\%)\end{array}$ & \\
\hline \multirow{4}{*}{$\begin{array}{c}\text { What is the reason for } \\
\text { changing the dose of your } \\
\text { drugs? }\end{array}$} & Worsening of symptoms & $53(9.8)$ & $6(1.1)$ & \multirow{4}{*}{0.005} \\
\hline & Improvement of symptoms & $146(27)$ & $11(2)$ & \\
\hline & $\begin{array}{l}\text { Reduction of } \\
\text { complications }\end{array}$ & $137(25.5)$ & $11(2)$ & \\
\hline & Other cases & $175(32.4)$ & $1(0.2)$ & \\
\hline
\end{tabular}

${ }^{*}$ Chi-square test

\section{Discussion}

Based on the results of this study, there was no significant relationship between the overall health literacy level and performance of self-medication by women. Given that the health literacy level was inadequate among the vast majority of the women and not very adequate among an insignificant number of women, all the women under study had low health literacy level regardless of confirmation and performance of self-medication by them.
Based on the review of the existing literature, a limited number of studies have examined the relationship between these two components. The studies have mainly focuses on the relationship between health literacy and drug compliance, health status and healthy behaviors, the impact of training programs on self-medication, and etc. Among these studies, a study on the relationship between health literacy and drug compliance among patients with glaucoma can be noted; the researchers in this study reported that patients with 
poor health literacy showed less drug compliance (33).

Moreover, in other studies, the researchers also reported a significant relationship between understanding medication orders and health literacy (34) and drug self-management skills (35). The results of other studies revealed that the implementation of an electronic interventional personal training program could be effective on modifying the self-medication behaviors of the elderly with hypertension (36). Only one study was found on the relationship between health literacy and self-medication in the general population of Ardabil City, Iran, and the researchers in the study reported a significant relationship between health literacy and self-medication in their research community (37). It should be noted that the research community in this study was the public population and the investigation tool for selfmedication behaviors included four questions designed by the researcher. It seemed that selfmedication behaviors among the women under study took place independently of health literacy and under the influence of other factors.

Based on the results of the present study, the drugs used by the women for self-medication were mostly for the treatment of colds and included, respectively, analgesics, antibiotics, anti-allergy drugs, and hypnotics; the results were more or less similar to those of other studies. For instance, in a previous study, cold and coughing were the most common causes of self-medication (38), and in another study, self-medication drugs used among adolescents consisted of non-steroidal antiinflammatory drugs (NSAIDs) or analgesics, cold stop and anti-cough drugs, anti-allergy drugs, and anti-acids (39). In another study conducted in Iran, herbal medicines had the highest rate, followed by analgesics and antibiotics, in the self-medication program of the people (37). In the present study, self-medication was considered as haphazard treatment with chemical drugs. Perhaps the process of choosing and taking herbal drugs has a different pattern compared to chemical drugs.

The results of this study showed that there was a high incidence of changes in the type and dosage of the drug among the women under study. In addition, the women only paid attention to the instructions inside the drug box to acquire information on their use, and only a few of the women considered the expiry date of the drugs. Overall, these results indicate a high incidence of unsuitable self-medication behaviors among women in the study, while in another study, drug use with a high dosage among adolescents and lack of studying of drug labeling were reported as $21.6 \%$ and $10.1 \%$, respectively (39). This indicates a higher incidence of incorrect self-medication behaviors with increased age and adulthood.

In this study, over $89.0 \%$ of women approved selfmedication and more than $98 \%$ of them performed self-medication. A study has reported that more than half of the people in India believed that selfmedication was often healing (40). However, the incidence of self-medication in other environments like the public population of Ardebil City, Iran, and European countries was $45.8 \%$ (39) and $61.6 \%$ (37), respectively. The higher incidence of selfmedication behaviors in the present study was likely related to the nature of the research community (women), as the results of numerous studies indicated the higher incidence of selfmedication among women compared to men (17, 41).

According to the results of this study, women referred to the medication guide for the information they needed to determine the dosage and how to store the drug at home; however, in other studies, individuals referred to their own experiences for self-medication (42). Accordingly, due to the low level of health literacy of the subjects, it is not expected that they would refer to individual competencies.

Since low health literacy level is one of the major challenges for health policy-making and healthy lifestyle and behaviors, efforts to gain these skills are recommended along with public health promotion programs. Moreover, improving health literacy is part of the Healthy People 2020 program (43). Furthermore, in the strategic document of the health system policies of the Islamic Republic of Iran, the promotion of health information, accountability, structured ability, and participation of the individual, family and society in provision, preservation, and promotion of health are of the priorities of the health system, using the capacity of cultural, educational, and media entities, and organizations under the supervision of the Ministry of Health, Treatment, and Medical Education (29). Generally, the results of this study showed significant differences in both the health literacy level and self-medication behaviors and the relationship between these two components with the results of similar studies. Therefore, low level of health literacy and high incidence of selfmedication behaviors among the women under study require comprehensive planning and measures of health authorities of the study community.

Undoubtedly, the limitations associated with the study method should be taken into account in generalizing the results of this study. Moreover, due to the complexity of health behaviors in different societies and also the self-reporting of 
self-medication behaviors, the repetition of this study is recommended using more precise methods and controlling of important interventional factors.

\section{Conclusion}

The vast majority of women had inadequate health literacy level and, while approving self-medication actions, most of them reported incorrect selfmedication behaviors. Moreover, no relationship was found between the two components. A review of women's health programs and the empowerment of the women under study to promote health literacy skills seem necessary.

\section{Acknowledgments}

This essay has been derived from a master's thesis. The researchers wish to thank the respected vice-chancellor of research and technology of Rafsanjan University of Medical Sciences for the financial support of this study, the employees of health service centers of Sirjan City, and all the women who collaborated in the implementation of this study.

\section{Conflict of interest: None declared.}

\section{References}

1. Wertheimer Al, Serradell J. A discussion paper on self-care and its implications for pharmacists. Pharm World Sci 2008; 30(4):309-15.

2. Fathelrahman $A$, Ibrahim $M$, Wertheimer $A$. Pharmacy practice in developing countries. 1st ed. Cambridge, Massachusetts, United States: Academic Press; 2016.

3. Shaghaghi A, Asadi $M$, Allahverdipour $H$. Predictors of self-medication behavior: a systematic review. Iran J Public Health 2014; 43(2):136-46.

4. World Health Organization. The role of the pharmacist in self-care and self-medication. Department of Essential Drugs and Other Medicines, World Health Organization. Hague, Netherlands: Report of the 4th WHO Consultative Group on the Role of the Pharmacist; 26-28 August 1998.

5. Verma RK, Mohan L, Pandey M. Evaluation of self medication among professional students in North India: proper statutory drug control must be implemented. Asian J Pharm Clin Res 2010; 3(1):60-4.

6. Osemene K, Lamikanra A. A study of the prevalence of self-medication practice among university students in Southwestern Nigeria. Trop J Pharm Res 2012; 11(4):683-9.

7. Selvaraj K, Kumar SG, Ramalingam A. Prevalence of self-medication practices and its associated factors in Urban Puducherry, India. Perspect Clin Res 2014; 5(1):32-6.

8. Skliros E, Merkouris P, Papazafiropoulou A, Gikas A, Matzouranis G, Papafragos C, et al. Self-medication with antibiotics in rural population in Greece: a cross-sectional multicenter study. BMC Fam Pract 2010; 11:58.

9. Domingues PH, Galvão TF, Andrade KR, Sá PT, Silva MT, Pereira MG. Prevalence of selfmedication in the adult population of Brazil: a systematic review. Rev Saude Publica 2015; 49 36.

10. Jerez-Roig J, Medeiros LF, Silva VA, Bezerra CL, Cavalcante LA, Piuvezam G, et al. Prevalence of self-medication and associated factors in an elderly population: a systematic review. Drugs Aging 2014; 31(12):883-96.

11. Yadav S, Rawal G. Self-medication practice in low income countries. International Journal of Pharmaceutical Chemistry and Analysis 2015; 2(3):139-42.

12. Azami-Aghdash S, Mohseni M, Etemadi $M$, Royani S, Moosavi A, Nakhaee M. Prevalence and cause of self-medication in Iran: a systematic review and meta-analysis article. Iran J Public Health 2015; 44(12):1580-93.

13. Hughes CM, McElnay JC, Fleming GF. Benefits and risks of self medication. Drug Saf 2001; 24(14):1027-37.

14. Ruiz ME. Risks of self-medication practices. Curr Drug Saf 2010; 5(4):315-23.

15. Kasim K, Hassan $H$. Self medication problem in egypt: a review of current and future perspective. Int J Cur Res Rev 2018; 10(4):40-5.

16. Alfalogy $\mathrm{EH}$, Nafadi $\mathrm{HB}, \mathrm{Al}$ Rehaili $\mathrm{SH}, \mathrm{AL}-\mathrm{Harbi}$ BA. Prevalence and predictors of self-medication with antibiotics for children in Makkah, Saudi Arabi. European Journal of Preventive Medicine 2017; 5(5):60-4.

17. Pons EDS, Knauth DR, Vigo Á, PNAUM Research Group, Mengue SS. Predisposing factors to the practice of self-medication in Brazil: Results from the National Survey on Access, Use and Promotion of Rational Use of Medicines (PNAUM). PloS One 2017; 12(12):e0189098.

18. Das M, Choudhury S, Santra R, De R, Roy RK. The extent and factors associated with nonprescription medicine use in Eastern India - A cross-sectional survey. J Young Pharm 2017; 9(4):583-7.

19. Cadman KP. Lay worker health literacy: A concept analysis and operational definition. Nurs Forum 2017; 52(4):348-56.

20. Sherazi BA, Mahmood KT, Amin F, Zaka M, Riaz $M$, Javed $A$. Prevalence and measure of self medication: a review. Journal of Pharmaceutical Sciences and Research 2012; 4(3):1774-8.

21. Kulkarni P, Garg A, Ajmera A, Mahajan A, Gadekar S, Kulkarni P. Global scenario of self medication: A review of literature. Indian Journal of Commerce \& Management Studies 2018; 9(1):99-107.

22. Chen ML, Chan HS, Chu HY, Chou LN. Medication knowledge, safe use of medicines and health literacy in Southern Taiwan: a crosssection study. Br J Med Med Res 2016; 16(3):18.

23. Persell SD, Osborn CY, Richard R, Skripkauskas S, Wolf MS. Limited health literacy is a barrier to medication reconciliation in ambulatory care. J Gen Intern Med 2007; 22(11):1523-6. 
24. Shieh C, Broome ME, Stump TE. Factors associated with health information-seeking in low-income pregnant women. Women Health 2010; 50(5):426-42.

25. Wang MP, Viswanath K, Lam TH, Wang X, Chan SS. Social determinants of health information seeking among Chinese adults in Hong Kong. PloS One 2013; 8(8):e73049.

26. Boudioni M, McPherson K, Moynihan C, Melia J, Boulton M, Leydon $G$, et al. Do men with prostate or colorectal cancer seek different information and support from women with cancer? Br J Cancer 2001; 85(5):641-8.

27. Reczek C, Umberson D. Gender, health behavior, and intimate relationships: lesbian, gay, and straight contexts. Soc Sci Med 2012; 74(11):1783-90.

28. Schmiedl S, Rottenkolber M, Hasford J, Rottenkolber D, Farker K, Drewelow B, et al. Self-medication with over-the-counter and prescribed drugs causing adverse-drug-reactionrelated hospital admissions: results of a prospective, long-term multi-centre study. Drug Saf 2014; 37(4):225-35.

29. Marniati, Notoatmodjo S, Kasiman S, kintoko Rohadi R. Patient's behaviour with coronary heart desease viewed from socio-cultural aspect of aceh society in Zainoel Abidin hospital. MATEC Web of Conferences 2018; 150(05065):p12.

Doi: 10.1051/matecconf/201815005065.

30. Baghianimoghadam $\mathrm{MH}$, Mojahed $\mathrm{S}$, Baghianimoghadam M, Yousefi N, Zolghadr R. Attitude and practice of pregnant women regarding self-medication in Yazd, Iran. Arch Iran Med 2013; 16(10):580-3.

31. Montazeri A, Tavousi M, Rkhshani F, Azin SA, Jahangiri $\mathrm{K}$, Ebadi $\mathrm{M}$, et al. Health Literacy for Iranian Adults (HELIA): development and psychometric properties. Payesh 2014; 13(5):589-99.

32. DeVellis RF. Scale development: theory and applications. $4^{\text {th }}$ ed. Thousand Oaks, California, United States: SAGE Publications; 2016.

33. Muir KW, Santiago-Turla C, Stinnett SS, Herndon LW, Allingham RR, Challa $P$, et al. Health literacy and adherence to glaucoma therapy. Am J Ophthalmol 2006; 142(2):223-6.
34. Waldrop-Valverde $\mathrm{D}$, Jones $\mathrm{DL}$, Jayaweera $\mathrm{D}$, Gonzalez P, Romero J, Ownby RL. Gender differences in medication management capacity in HIV infection: the role of health literacy and numeracy. AIDS Behav 2009; 13(1):46-52.

35. Kripalani S, Henderson LE, Chiu EY, Robertson R, Kolm P, Jacobson TA. Predictors of medication self-management skill in a low-literacy population. J Gen Intern Med 2006; 21(8):852-6.

36. Neafsey PJ, M'lan CE, Ge M, Walsh SJ, Lin CA, Anderson $E$. Reducing adverse self-medication behaviors in older adults with hypertension: results of an e-health clinical efficacy trial. Ageing Int 2011; 36(2):159-91.

37. Kamran A, Sharifirad G, Shafaeei Y, Mohebi S. Associations between self-medication, health literacy, and self-perceived health status: A community-based study. lint J Prev Med 2015; 6:66.

38. Lei X, Jiang H, Liu C, Ferrier A, Mugavin J. Selfmedication practice and associated factors among residents in wuhan, China. Int $\mathrm{J}$ Environ Res Public Health 2018; 15(1). Pii:E68.

39. Lee CH, Chang FC, Hsu SD, Chi HY, Huang LJ, Yeh MK. Inappropriate self-medication among adolescents and its association with lower medication literacy and substance use. PloS One 2017; 12(12):e0189199.

40. Jha A, Unnikrishnan MK, Shanbhag R. A survey in Indian population on attitude to selfmedication. Adv Sci Lett 2017; 23(3):1983-6.

41. Lukovic JA, Miletic V, Pekmezovic T, Trajkovic G, Ratkovic N, Aleksic D, et al. Self-medication practices and risk factors for self-medication among medical students in Belgrade, Serbia. PloS One 2014; 9(12):e114644.

42. Pan H, Cui B, Zhang D, Farrar J, Law F, BaThein W. Prior knowledge, older age, and higher allowance are risk factors for self-medication with antibiotics among university students in southern China. PloS One 2012; 7(7):e41314.

43. Braithwaite $T$, Winford $B$, Bailey $H$, Bridgemohan $P$, Bartholomew D, Singh D, et al. Health system dynamics analysis of eyecare services in Trinidad and Tobago and progress towards Vision 2020 Goals. Health Policy Plan 2017; 33(1):70-84. 